\title{
A MORTALIDADE DOS SOBREIROS E A SECA
}

\author{
TERESA S. DAVID(1) \\ MARIA TERESA CABRAL(2) \\ RAÚL M. A. SARDINHA(3)
}

\section{INTRODUÇÃO}

A subericultura portuguesa foi sobressaltada por preocupações decorrentes de um surto anormal de mortalidade, com início em 1988.

A ocorrência de picos de mortalidade tem vindo periodicamente a alarmar as actividades do sector e causas de natureza vária, alogénicas ou autogénicas, vêm sendo consideradas causadoras deste distúrbio. A esta mortalidade foi logo associada a ideia de que uma "doença do sobreiro" estava a dizimar esta espécie. O diagnóstico feito demonstrou que as pragas e doenças associadas ao declínio eram não causas mas consequência deste. Entre estas causas ressaltam as de ordem estrutural, de condução dos povoamentos e as abióticas. Dentre as primeiras, um inquérito feito aos sistemas de exploração praticados na região estudada demonstrou que prevalecem sistemas de arrendamento do solo sobrepondo-se numa mesma área interesses diferentes: o do proprietário que explora a cortiça e o do rendeiro a quem interessa maximizar a produçăo agrícola ou a pastorícia. No que se refere à conduçăo e exploração dos povoamentos verificou-se que se abandonaram práticas tradicionais, as quais foram substituídas por outras nem sempre adequadas, sem ter em conta as condiçōes edafo-climáticas em que os montados vege-

\footnotetext{
(1) Técnica superior

(2) Investigadora principal

(3) Professor catedrático

Estação Florestal Nacional, Tapada Nacional das Necessidades, 1300 Lisboa, Portugal, Fax. (351-1) 3973163
} 
tam. Quanto aos restantes factores abióticos foi também possível relacionar a maior mortalidade com determinadas condições de fisiografia, solos e clima. Relativamente à fisiografia verificou-se que a maior mortalidade nesta região ocorre nas encostas de exposição sul, nas linhas de água, nas baixas a que está associado hidromorfismo e nos topos decapitados. Quanto aos solos verificou-se serem os derivados de xisto aqueles a que corresponde maior mortalidade bem como os argiluviados, para-hidromórficos ou solos com características aproximadas. De um modo geral solos de baixo arejamento e fraca capacidade de infiltração são também adversos ao sobreiro, que desta forma é mais susceptível.

No que se refere ao clima a seca é frequentemente apontada como possível causa primária.

A ênfase posta neste factor mostrou ser assim oportuno proceder ao estudo das variações climáticas no último século, salientando em particular os aspectos relativos aos principais períodos secos considerados pela bibliografia como possíveis indutores de situações de elevada mortalidade dos sobreiros. As mais antigas referências a estas situações remontam ao final do século passado (PESTANA, 1898, 1899; RAMIRES, 1898/99, 1899).

Em 1927 e 1931, Silva Tavares e Branquinho de Oliveira referem novas situações de mortalidade de sobreiros no Vale do Tejo, que atribuem a doenças. Nos anos 40, NEVES $(1945,1949,1954)$ e PIMENTEL (1946) referem igualmente uma elevada mortalidade dos sobreiros no Vale de Santarém e em Alpiarça. Nestes estudos a mortalidade é relacionada com a ocorrência de anos de seca e com a utilização de técnicas de intervenção cultural incorrectas as quais são também insistentemente referidas, no mesmo contexto, por NATIVIDADE (1950), NOGUEIRA (1978) e JEAN-MARC OLIVIER. Segundo NEVES (1949) a ocorrência de situações de mortalidade pode ser imputável a uma má gestão dos ecossistemas, com lavouras profundas, arroteias de matos, culturas agrícolas esgotantes, podas exageradas, exploração excessiva de cortiça e à interacção de pragas e doenças. De facto, e embora surtos de elevada mortalidade do sobreiro tenham ocorrido periodicamente, pelo menos desde há um século, as causas subjacentes ou os factores que os predispõem não têm sido sistematicamente identificados. Na verdade, NEVES (1954) ao referir-se à mortalidade diz que "... àparte informações complementares que obteve sobre a importância económica e dispersão da doença, nada mais se fez com a profundidade e rigor científico indispensáveis". 


\section{EVOLUÇÃO CLIMÁTICA NO LITORAL ALENTEJANO \\ DE 1932 A 1990}

No âmbito de um estudo sobre o diagnóstico das causas de mortalidade do sobreiro nos concelhos de Santiago de Cacém, Grândola e Sines (CABRAL e SARDINHA, 1992) que decorreu na Estaçăo Florestal Nacional entre 1988 e 1991, foi possível relacionar-se a mortalidade com períodos de seca.

Para caracterização dos principais períodos secos ocorridos na região em estudo, recorreu-se aos registos mensais de precipitação das estações meteorológicas de Alvalade, Grândola e Cercal do Alentejo, cedidos pela Direç̧ăo Geral dos Recursos Naturais.

A análise das precipitações anuais foi feita com base no ano hidrológico definido de Setembro a Agosto dado que, nas nossas condições climáticas, Setembro corresponde ao início do período chuvoso, definição essa que coincide com a apresentada em FEIO e HENRIQUES (1986). Na figura 1, apresentam-se, a título de exemplo, os valores referentes à estação meteorológica de Grândola.

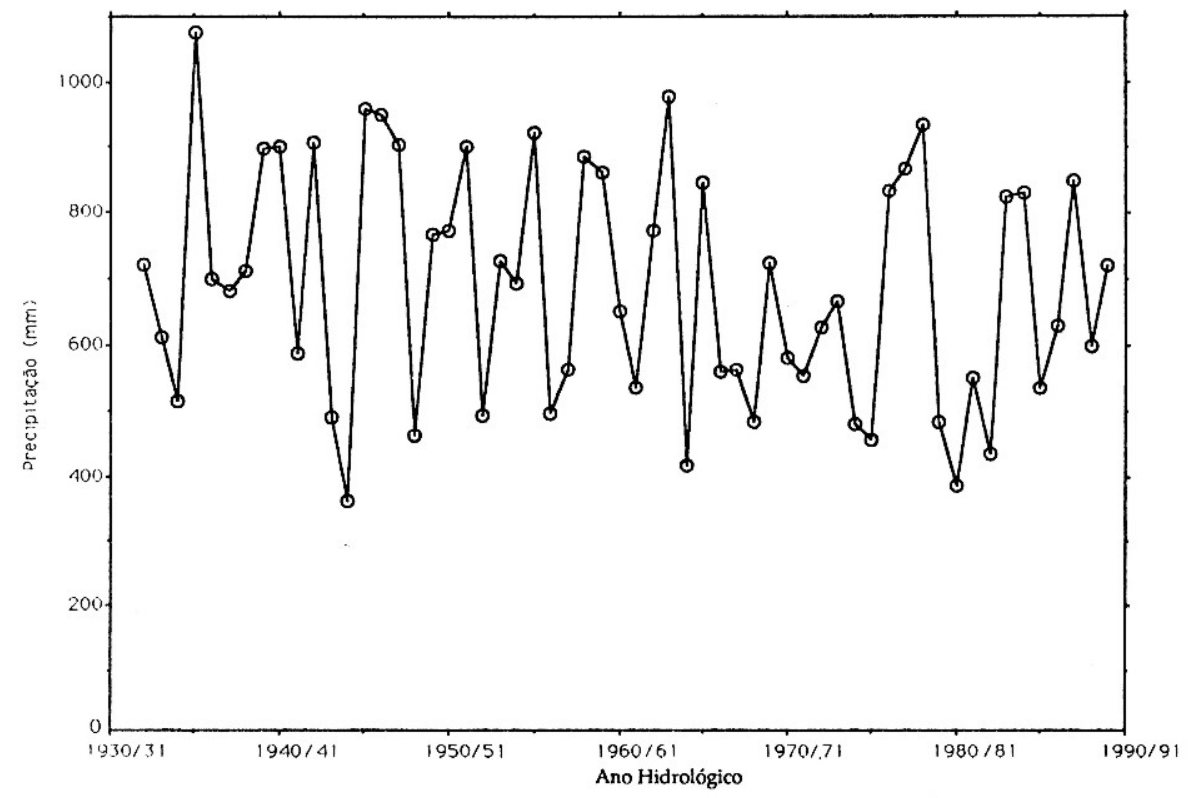

Figura 1 - Evolução da precipitação anual no período de 1932/331989/90, para a estação meteorológica de Grândola.

A caracterização dos períodos mais secos incidiu sobre os totais anuais e estacionais relativos ao período de 1932/33 a 1989/90. 
Para cada um dos anos considerados determinaram-se as percentagens de precipitação ocorrida relativamente às médias anuais e estacionais do intervalo de tempo considerado (58 anos), de acordo com as principais secas referenciadas em FEIO e HENRIQUES (1986), GONÇALVES (1982) e PARREIRA (1982) (quadros I e II). De salientar que nestes trabalhos se encontram algumas diferenças na definição dos períodos secos, as quais provêm

\begin{tabular}{|c|c|c|c|c|c|c|c|c|c|c|c|c|}
\hline \multirow{2}{*}{$\begin{array}{c}\text { Estaçăo } \\
\text { meteoro- } \\
\text { lógica }\end{array}$} & \multirow{2}{*}{$\begin{array}{l}\text { Ano } \\
\text { hidro- } \\
\text { lógico } \\
\text { (Set/ } \\
\text { /Ago) }\end{array}$} & \multirow{2}{*}{$\begin{array}{c}\text { Prec. } \\
\text { médla } \\
\text { anual } \\
1932 / 33 \\
1989 / 90\end{array}$} & \multicolumn{2}{|c|}{$\begin{array}{c}\text { Precipltaçáo } \\
\text { anual }\end{array}$} & \multicolumn{2}{|c|}{$\begin{array}{c}\text { Precipltaçăo } \\
\text { Set/Nov }\end{array}$} & \multicolumn{2}{|c|}{$\begin{array}{c}\text { Precipltaçáo } \\
\text { Dez/Fev }\end{array}$} & \multicolumn{2}{|c|}{$\begin{array}{c}\text { Precipltaçáo } \\
\text { Mar/Mal }\end{array}$} & \multicolumn{2}{|c|}{$\begin{array}{l}\text { Preclpltaçáo } \\
\text { Jun/Ago }\end{array}$} \\
\hline & & & $(\mathrm{mm})$ & $\begin{array}{c}\text { em \% v. } \\
\text { médlo } \\
1932 / 90\end{array}$ & $(\mathrm{~mm})$ & $\begin{array}{c}\text { em \% v. } \\
\text { médlo } \\
1932 / 90\end{array}$ & $(\mathrm{~mm})$ & $\begin{array}{c}\text { em \% v. } \\
\text { médio } \\
1932 / 90\end{array}$ & $(\mathrm{~mm})$ & $\begin{array}{c}\text { em \% v. } \\
\text { médio } \\
1932 / 90\end{array}$ & $(\mathrm{~mm})$ & $\begin{array}{c}\text { em \% v. } \\
\text { médio } \\
1932 / 90\end{array}$ \\
\hline $\begin{array}{l}\text { Alvalade } \\
37^{\circ} 11^{\prime} \mathrm{N} \\
8^{\circ} 24^{\prime} \mathrm{W} \\
\text { Alt. } 47 \mathrm{~m}\end{array}$ & $\begin{array}{l}1944 / 45 \\
1948 / 49 \\
1975 / 76 \\
1980 / 81 \\
1982 / 83 \\
\end{array}$ & 543.6 & $\begin{array}{l}305.0 \\
405.5 \\
384.9 \\
294.6 \\
309.3 \\
\end{array}$ & $\begin{array}{l}56.1 \\
74.6 \\
70.8 \\
54.2 \\
56.9 \\
\end{array}$ & $\begin{array}{r}145.5 \\
115.1 \\
46.7 \\
141.6 \\
151.7 \\
\end{array}$ & $\begin{array}{r}95.0 \\
75.2 \\
30.5 \\
92.5 \\
99.1 \\
\end{array}$ & $\begin{array}{r}85.0 \\
213.5 \\
154.7 \\
27.6 \\
48.3 \\
\end{array}$ & $\begin{array}{r}37.4 \\
94.0 \\
68.1 \\
12.2 \\
21.3 \\
\end{array}$ & $\begin{array}{r}73.8 \\
60.2 \\
174.1 \\
120.2 \\
100.3 \\
\end{array}$ & $\begin{array}{r}50.6 \\
41.3 \\
119.4 \\
82.4 \\
68.8 \\
\end{array}$ & $\begin{array}{r}0.7 \\
16.7 \\
9.4 \\
5.2 \\
9.0 \\
\end{array}$ & $\begin{array}{r}3.9 \\
93.8 \\
52.8 \\
29.2 \\
50.6 \\
\end{array}$ \\
\hline $\begin{array}{l}\text { Grândola } \\
38^{\circ} 11^{\prime} \mathrm{N} \\
8^{\circ} 33^{\prime} \mathrm{W} \\
\text { Alt. } 94 . \mathrm{m}\end{array}$ & $\begin{array}{l}1944 / 45 \\
1948 / 49 \\
1975 / 76 \\
1980 / 81 \\
1982 / 83 \\
\end{array}$ & 688,9 & $\begin{array}{l}362.7 \\
463.2 \\
458.0 \\
388.2 \\
436.4 \\
\end{array}$ & $\begin{array}{l}52.6 \\
67.2 \\
66.5 \\
56.4 \\
63.3 \\
\end{array}$ & $\begin{array}{r}126.4 \\
72.0 \\
58.8 \\
145.8 \\
178.9 \\
\end{array}$ & \begin{tabular}{r|}
73.3 \\
41.8 \\
34.1 \\
84.6 \\
103.8 \\
\end{tabular} & \begin{tabular}{r|}
137.0 \\
271.0 \\
230.6 \\
38.4 \\
77.2 \\
\end{tabular} & $\begin{array}{l}43.9 \\
86.7 \\
73.8 \\
12.6 \\
24.7 \\
\end{array}$ & \begin{tabular}{r|}
88.7 \\
100.4 \\
152.6 \\
201.4 \\
163.4 \\
\end{tabular} & $\begin{array}{r}48.0 \\
54.4 \\
82.6 \\
109.0 \\
88.5 \\
\end{array}$ & $\begin{array}{r}10.6 \\
19.8 \\
16.0 \\
1.6 \\
16.9 \\
\end{array}$ & $\begin{array}{r}54.6 \\
102.1 \\
82.5 \\
8.2 \\
87.1 \\
\end{array}$ \\
\hline $\begin{array}{r}\text { Cercal } \\
37^{\circ} 48^{\prime} \mathrm{N} \\
8^{\circ} 40^{\prime} \mathrm{W} \\
\text { Att. } 176 \mathrm{~m}\end{array}$ & $\begin{array}{l}1944 / 45 \\
1948 / 49 \\
1975 / 76 \\
1980 / 81 \\
1982 / 83\end{array}$ & 790.2 & \begin{tabular}{|l|}
522.1 \\
450.1 \\
558.3 \\
461.0 \\
478.9
\end{tabular} & $\begin{array}{l}66.1 \\
57.0 \\
70.7 \\
58.3 \\
60.6\end{array}$ & \begin{tabular}{r|}
266.0 \\
38.6 \\
59.5 \\
219.7 \\
224.5 \\
\end{tabular} & $\begin{array}{r}129.4 \\
18.8 \\
28.9 \\
106.9 \\
109.2 \\
\end{array}$ & \begin{tabular}{|r|r|}
167.6 \\
298.7 \\
252.2 \\
58.7 \\
98.5 \\
\end{tabular} & $\begin{array}{l}48.2 \\
85.8 \\
72.5 \\
16.9 \\
28.3 \\
\end{array}$ & \begin{tabular}{|r|r|}
88.8 \\
93.4 \\
236.2 \\
178.8 \\
141.5
\end{tabular} & \begin{tabular}{r|}
41.6 \\
43.7 \\
110.6 \\
83.7 \\
66.2 \\
\end{tabular} & $\begin{array}{r}0.0 \\
19.4 \\
10.4 \\
3.8 \\
14.4\end{array}$ & $\begin{array}{r}0.0 \\
84.3 \\
45.2 \\
16.5 \\
62.6 \\
\end{array}$ \\
\hline
\end{tabular}

\section{Quadro I- Caracterização dos principais períodos de seca referenciados em FEIO e HENRIQUES (1986)}

\begin{tabular}{|c|c|c|c|c|c|c|c|c|c|c|c|c|}
\hline \multirow{2}{*}{$\begin{array}{c}\text { Estação } \\
\text { meteoro- } \\
\text { lógica }\end{array}$} & \multirow{2}{*}{$\begin{array}{c}\text { Ano } \\
\text { hidro- } \\
\text { lóglco } \\
\text { (Set/ } \\
\text { (Ago) }\end{array}$} & \multirow{2}{*}{$\begin{array}{c}\text { Prec. } \\
\text { média } \\
\text { anual } \\
1932 / 33 \\
1989 / 90\end{array}$} & \multicolumn{2}{|c|}{$\begin{array}{c}\text { Preclpltaçáo } \\
\text { anual }\end{array}$} & \multicolumn{2}{|c|}{$\begin{array}{c}\text { Precipltação } \\
\text { Set/Nov }\end{array}$} & \multicolumn{2}{|c|}{$\begin{array}{c}\text { Precipltaçào } \\
\text { Dez/Fev }\end{array}$} & \multicolumn{2}{|c|}{$\begin{array}{c}\text { Precipitaçáo } \\
\text { Mar/Mal }\end{array}$} & \multicolumn{2}{|c|}{$\begin{array}{c}\text { Precipltaçāo } \\
\text { Jun/Ago }\end{array}$} \\
\hline & & & $(\mathrm{mm})$ & $\begin{array}{c}\text { em \% v. } \\
\text { médlo } \\
1932 / 90\end{array}$ & $(\mathrm{~mm})$ & $\begin{array}{c}\text { em \% v. } \\
\text { médlo } \\
1932 / 90\end{array}$ & $(\mathrm{~mm})$ & $\begin{array}{c}\text { em \% v. } \\
\text { médlo } \\
1932 / 90\end{array}$ & $(\mathrm{~mm})$ & $\begin{array}{c}\text { em \% v. } \\
\text { médlo } \\
1932 / 90\end{array}$ & $(\mathrm{~mm})$ & $\begin{array}{c}\text { em \% v. } \\
\text { médlo } \\
1932 / 90\end{array}$ \\
\hline $\begin{array}{l}\text { Avalade } \\
37^{\circ} 11^{\prime} \mathrm{N} \\
8^{\circ} 24^{\prime} \mathrm{W} \\
\text { Alt. } 47 \mathrm{~m}\end{array}$ & $\begin{array}{l}1934 / 35 \\
1943 / 44 \\
1952 / 53 \\
1956 / 57 \\
1957 / 58 \\
1964 / 65\end{array}$ & 543.6 & $\begin{array}{l}336.0 \\
279.1 \\
363.0 \\
405.0 \\
378.4 \\
322.7\end{array}$ & $\begin{array}{l}61.8 \\
51.3 \\
66.8 \\
74.5 \\
69.6 \\
59.4\end{array}$ & $\begin{array}{r}62.6 \\
68.5 \\
97.0 \\
92.3 \\
113.0 \\
62.0 \\
\end{array}$ & $\begin{array}{l}40.9 \\
44.8 \\
63.4 \\
60.3 \\
73.8 \\
40.5\end{array}$ & $\begin{array}{r}110.6 \\
79.1 \\
171.0 \\
151.4 \\
167.4 \\
136.8\end{array}$ & $\begin{array}{l}48.7 \\
34.8 \\
75.3 \\
66.7 \\
73.7 \\
60.2\end{array}$ & $\begin{array}{r}150.4 \\
82.2 \\
94.7 \\
134.5 \\
76.7 \\
93.5\end{array}$ & $\begin{array}{r}103.2 \\
56.4 \\
65.0 \\
92.2 \\
52.6 \\
64.1\end{array}$ & $\begin{array}{r}12.4 \\
49.3 \\
0.3 \\
26.8 \\
21.3 \\
30.4\end{array}$ & $\begin{array}{r}69.7 \\
277.0 \\
1.7 \\
150.6 \\
119.7 \\
170.8\end{array}$ \\
\hline $\begin{array}{c}\text { Grândola } \\
38^{\circ} 11^{\prime} \mathrm{N} \\
8^{\circ} 33^{\prime} \mathrm{W} \\
\text { Alt. } 94 . \mathrm{m}\end{array}$ & $\begin{array}{l}1934 / 35 \\
1943 / 44 \\
1952 / 53 \\
1956 / 57 \\
1957 / 58 \\
1964 / 65\end{array}$ & 688.9 & $\begin{array}{l}515.2 \\
489.7 \\
492.8 \\
496.6 \\
564.4 \\
416.6\end{array}$ & $\begin{array}{l}74.8 \\
71.1 \\
71.5 \\
72.1 \\
81.9 \\
60.5\end{array}$ & $\begin{array}{r}88.2 \\
131.0 \\
112.2 \\
77.2 \\
84.6 \\
74.0\end{array}$ & $\begin{array}{l}51.2 \\
76.0 \\
65.1 \\
44.8 \\
49.1 \\
42.9\end{array}$ & $\begin{array}{l}263.4 \\
198.1 \\
281.8 \\
190.2 \\
323.6 \\
217.0\end{array}$ & $\begin{array}{r}84.3 \\
63.4 \\
90.2 \\
60.9 \\
103.6 \\
69.5\end{array}$ & $\begin{array}{r}142.8 \\
111.8 \\
97.0 \\
209.0 \\
112.4 \\
123.0\end{array}$ & $\begin{array}{r}77.3 \\
60.5 \\
52.5 \\
113.2 \\
60.9 \\
66.6\end{array}$ & $\begin{array}{r}20.8 \\
48.8 \\
1.8 \\
20.2 \\
43.8 \\
2.6\end{array}$ & $\begin{array}{r}107.2 \\
251.5 \\
8.3 \\
104.1 \\
225.8 \\
13.4\end{array}$ \\
\hline
\end{tabular}

Quadro II - Caracterização de outros períodos de seca com especial incidência na região em estudo 
do facto de no primeiro caso se definir o ano hidrológico de Setembro a Agosto e nos outros de Janeiro a Dezembro.

Do estudo realizado parece ressaltar uma certa coincidência entre a ocorrência de períodos de seca e a oclusão de mortalidade anormal dos sobreiros, que pode ser evidenciada pela correspondência temporal existente entre os principais períodos de seca e as mais relevantes citações bibliográficas sobre mortalidade (quadro III).

\begin{tabular}{||c|c||}
\hline $\begin{array}{c}\text { Anos de seca } \\
\text { deste século }\left(^{\star}\right)\end{array}$ & $\begin{array}{c}\text { Bibliografia referindo anormal } \\
\text { mortalidade dos sobreiros }\end{array}$ \\
\hline \hline $1943-45$ & 1946 - Lopes Pimentel \\
& 1948 - Baeta Neves \\
$1975-76$ & 1978 - Serrão Nogueira \\
$1980-83$ & 1990 - Cabral \& Ferreira \\
& 1992 - Cabral \& Sardinha \\
\hline
\end{tabular}

(*) FEIO e HENRIQUES (1986)

Quadro III - Referências históricas aos surtos de mortalidade

A análise climática englobou ainda a evolução da precipitação ao longo dos 58 anos de registos, em termos anuais e estacionais, com vista à detecção de eventuais tendências de agravamento na magnitude das secas. Para tal, recorreu-se ao método das médias móveis $(\mathrm{Mm})$ para análise de séries temporais, com base em médias de ordem 11. Parece haver de facto uma certa tendência decrescente, no tempo das precipitações primaveris (Março a Maio), não sendo, no entanto, aparente qualquer variação tendencial para os restantes períodos estacionais. Na figura 2 ilustra-se esta tendência, comum às três estações meteorológicas, para a de Grândola.

\section{CONCLUSÕES}

Os dados em análise parecem evidenciar que existe uma convergência entre os surtos de seca e o incremento de mortalidade mais acentuada dos sobreiros.

Tendo em atenção, no entanto, o desfasamento entre a 
ocorrência da seca e os surtos de mortalidade no sobreiro, não parece evidente ser aquela um factor primário mas sim um factor predisponente que, conforme o grau de resiliência do ecossistema e a intensidade da gestão pouco adequada, o tornará mais ou menos susceptível às pragas e doenças que vêm sendo identificadas.

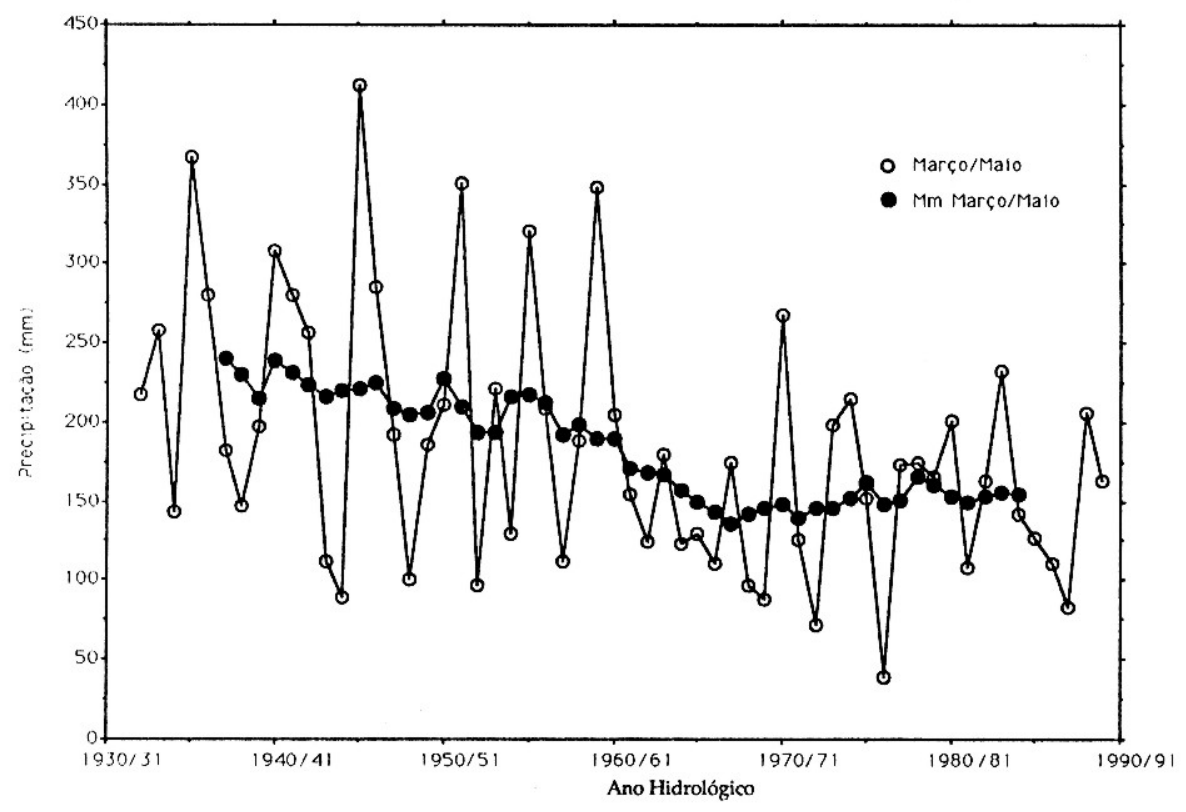

Figura 2 - Evolução da precipitação primaveril (Março/Maio) e da respectiva média móvel $(\mathrm{Mm})$ para a estação meteorológica de Grândola

\section{BIBLIOGRAFIA}

ALMEIDA, M. (1981) - Períodos de Seca em Portugal Continental. Revista do INMG 4(3 e 4).

CABRAL, M.; C. FERREIRA (1990) - Reflexões sobre a situaçăo dos montados de sobro. Revista Florestal, 4(2): 35-39.

CABRAL, M.; R. SARDINHA (1992) - Perspectiva integrada do declínio dos montados de sobro alentejanos. Actas do $2^{\circ}$ Encontro sobre os montados do sobro e azinho, SPCF, Évora.

FEIO, M.; V. HENRIQUES (1982) - As Secas de 1980-81 e de 1982-83 e as Principais Secas Anteriores. Intensidade e Distribuiçăo Regional. Memórias C.E.G., Lisboa. 
GONÇALVES, M. (1982) - Contribuição para o Estudo das Secas em Portugal Continental. Inst. Nac. Meteorol. Geofis., Lisboa.

NATIVIDADE, J. (1950) - Subericultura. D.G.S.F.A., Lisboa.

NEVES, C. B. (1949) - A seca dos sobreiros. Gazeta das Aldeias, 2168.

NEVES, C. B. (1954) - Doenças do sobreiro. A morte dos sobreiros no Vale do Tejo. Gazeta das Aldeias, 2284.

NOGUEIRA, C. S. (1978) - Bases ecológicas para o combate às pragas dos montados de sobro e azinho. Bol. Inst. Produtos Florestais.

OLIVEIRA, A. B. (1931) - Apontamentos para o estudo de duas doenças do sobreiro. Revista Agronómica, 19(1): 37-56.

PARREIRA, S. (1982) - Classificação dos Meses quanto à Precipitação, em Coimbra (1931-1975). Revista do INMG, 5 (1 a 4).

PESTANA, C. (1898) - Doenças do sobreiro. Arquivo Rural, 3(3).

PESTANA, C. (1899) - Doenças do sobreiro. Arquivo Rural, 4(6).

PIMENTEL, L. (1946) - O sobreiro também é parasitado pela Phytophthora cambivora (Petri) Buis., agente da doença da tinta do castanheiro. Publ. D. Geral Serv. Flores. Aquícolas, 13(1/2): 45-49.

RAMIRES, A. B. (1898) - O parasitismo do sobreiro, Portugal Agrícola, $10^{\circ}$ ano(8): 227-235.

RAMIRES, A. B. (1898/99) - Os parasitas do sobreiro. Portugal Agrícola, $10^{\circ}$ ano(9).

\section{Resumo}

Mortalidade dos sobreiros e a seca

O sobreiro tem vindo a ser periodicamente sujeito a pressões que the vêm causando declíneo e mortalidade. O complexo de relações envolvidas nos sistemas de produção determinou que a análise da "Determinação das Causas de Morte do Sobreiro nos Concelhos de Santiago do Cacém, Grândola e Sines", tivesse seguido um modelo integrado considerando os sub-sistemas físico, produtor, socio-económico e a diversidade de potenciais agentes de morte.

A análise dos inúmeros factores que interactuam revelou que o surto de morte anormal do sobreiro não resultou de uma única causa, mas antes da interacção de vários factores que predispõem, desencadeiam e aceleram a morte dos sobreiros.

Relaciona-se, neste trabalho, a incidência de anos particular- 
mente secos com o desencadeamento dos mais graves surtos de mortalidade. $O$ desfasamento identificado entre os dois fenómenos permitiu concluir serem os anos secos factores predisponentes que, conforme o grau de resilência do ecossistema e a maior ou menor eficácia da gestão agrícola, o tornarão mais ou menos susceptível às pragas e doenças que vêm sendo identificadas.

Palavras-chave: sobreiros, mortalidade, seca, declínio.

\section{Summary}

Drought influence on cork oak mortality

The cork oak forests have been periodically subject to hard stresses that caused growth decline and tree mortality. The results of the research entitled "Determination of death causes of cork oak in Santiago do Cacém, Grândola and Sines municipalities" revealed the complexity of the inter-related factors that occur in the system of production. An integrated approach was advised, considering the production, physical and socio-economic sub-systems as well as the diversity of potential cork oak death agents .

The analysis of a great number of factors involved revealed that death outbreak did not result from a single cause. It expresses the relationships among several factors which predispose, trigger and accelerate the death of the cork oak trees.

In this paper, particular attention is given to the extent and intensity of dry spells and its influence on cork trees mortality. The identified time lag between the two events led to the conclusion that intense and long dry seasons operate as a predisposing factor. This factor may intensify the degree of vulnerability to plagues and other diseases according to the degree of resilience of the ecosystem and the efficiency of the management practices.

Key-words: Cork oak mortality, drought, decline. 